\title{
NLC Positron Production Target
}

\author{
O.E. Krivosheev and \\ N.V. Mokhov \\ OSTI
}

RECEIVEO

M⿻上 22 1980

Fermi National Accelerator Laboratory

P.O. Box 500, Batavia, Illinois 60510

\section{S.I. Striganov}

Institute for High Energy Physics

Protvino, 142284, Russia

May 1996 


\section{Disclaimer}

This report was prepared as an account of work sponsored by an agency of the United States Government. Neither the United States Government nor any agency thereof, nor any of their employees, makes any warranty, expressed or implied, or assumes any legal liability or responsibility for the accuracy, completeness, or usefulness of any information, apparatus, product, or process disclosed, or represents that its use would not infringe privately owned rights. Reference herein to any specific commercial product, process, or service by trade name, trademark, manufacturer, or otherwise, does not necessarily constitute or imply its endorsement, recommendation, or favoring by the United States Government or any agency thereof. The views and opinions of authors expressed herein do not necessarily state or reflect those of the United States Government or any agency thereof. 


\title{
NLC Positron Production Target
}

\author{
O. E. Krivosheev, N. V. Mokhov and S. I. Striganov ${ }^{+}$ \\ Fermi National Accelerator Laboratory \\ P.O. Box 500, Batavia, Illinois 60510 \\ +Institute for High Energy Physics, Protvino, 142284, Russia \\ April 19, 1996
}

\begin{abstract}
The NLC positron production target is optimized with respect to positron yield, target integrity, cooling and shielding. Copper is proposed as a possible optimal choice.
\end{abstract}




\section{Introduction}

The proposed Next Linear Collider (NLC) is a $e^{+} e^{-}$linear collider with the $\mathrm{c}$. m. energy $500 \mathrm{GeV}$ in phase I and $1 \mathrm{TeV}$ in phase II [1]. One of the essential NLC components is a positron source for producing a low energy positron beam to be captured and accelerated. The positron production target design should take into account and properly balance the positron yield per initial electron, target integrity, shielding and thermal problems. In this study the EGS4 [3], GEANT3 [4] and MARS13 [5] Monte Carlo codes are used for electromagnetic shower simulations and the ANSYS code [6] for thermal and stress analyses. The positron yield and target behaviour are studied for a few target materials and configurations both for NLC-I and NLC-II beam parameters.

\section{Design and Calculation Parameters}

The relevant parameters of the NLC positron source for both the $0.5 \mathrm{TeV}$ and the $1 \mathrm{TeV}$ machines are presented in Table 1 [1]. For both phases, pulse duration is $126 \mathrm{~ns}$ and bunch spacing is $1.4 \mathrm{~ns}$.

Table 1: Positron source parameters.

\begin{tabular}{|l|r|r|}
\hline Parameter & NLC-I & NLC-II \\
\hline Energy $\mathrm{E}_{e^{-}}, \mathrm{GeV}$ & 3.11 & 6.22 \\
\hline No. of $e^{-}$per bunch & $1.50 \times 10^{10}$ & $1.50 \times 10^{10}$ \\
\hline No. of bunches per pulse & 90 & 90 \\
\hline No. of $e^{-}$per pulse & $1.35 \times 10^{12}$ & $1.35 \times 10^{12}$ \\
\hline Repetition rate, $\mathrm{Hz}$ & 180 & 120 \\
\hline Beam power, $\mathrm{kW}$ & 121 & 161 \\
\hline Beam RMS, $\mathrm{mm}$ & 1.2 & 1.6 \\
\hline Bunch intensity at IP & $0.84 \times 10^{10}$ & $1.24 \times 10^{10}$ \\
\hline
\end{tabular}

Positrons generated in the target are captured into a flux concentrator with the minimum radius of the internal cone $R_{\text {col }}=4.5 \mathrm{~mm}$ in the energy range 2 to $22 \mathrm{MeV}$. The positron bunch accelerated in the linac goes finally to the collider. According to $[1,2]$, one can get about $2.1 \times 10^{10}$ and $3.1 \times 10^{10}$ positrons per bunch from the disc tungsten target for NLC-I and NLC-II, respectively, that is a factor of 2.5 higher than the bunch intensity required at the interaction point (IP) (see Table 1).

It is assumed that the incident on the target electron beam has a Gaussian spatial distribution with $\sigma_{x}=\sigma_{y}=1.2(1.6) \mathrm{mm}$, a Gaussian energy distribution with $\sigma_{E}=$ $0.001 \times \mathrm{E}_{e}$ - and a Gaussian angular distribution with $\sigma_{\theta}=0.5 \mathrm{mrad}$. Calculations of the positron yield and energy deposition in the targets have been performed for 
the above electron beam parameters. All the three codes, EGS4, GEANT3 and MARS, predict both yield and energy deposition in a remarkable agreement with each other and with results of [1].

Tungsten gives a maximum positron yield, but it is fragile and has low specific heat and thermal conductivity, that leads to severe mechanical and cooling problems. A mitigation is possible with tungsten alloys. In the baseline design, the target is assumed to be made of a $W_{75} R_{25}$ tungsten-rhenium alloy with a thickness of 4 radiation length $\left(L_{R}\right)$. Experience at the Fermilab Pbar Source has shown an excellent behaviour of copper targets under extreme irradiation conditions (see below). Its relatively low $Z$ can result in somewhat decreased positron yield, but copper is far superior from the mechanical and thermal standpoints.

Both $W_{75} R_{25}$ and copper targets of various thicknesses are studied here. Three target configurations are considered: a disc of $R=100 \mathrm{~cm}$ radius, a cylinder of $R=4$ and $6 \mathrm{~mm}$ radius and a cone with the upstream radius $R_{1}=5 \mathrm{~mm}$ and the downstream one $R_{2}=3 \mathrm{~mm}$. The studies show that the maximum positron yield in the energy bin of 2 to $22 \mathrm{MeV}$ is from the $5 \mathrm{~L}_{R}$ tungsten $\left(\mathrm{W}_{75} \mathrm{R}_{25}\right)$ and $4 \mathrm{~L}_{R}$ copper targets. The energy deposition density at the downstream end of a $5 \mathrm{~L}_{R}$ tungsten target becomes too high, so, as in [1], we have accepted for $\mathrm{W}_{75} \mathrm{R}_{25}$ also the $4 \mathrm{~L}_{R}$ thickness.

\section{Positron Yield}

Figure 1 shows the calculated positron yield per incident electron for a disc tungsten target $4 \mathrm{~L}_{R}$ thick for several collection radii $\mathrm{R}_{\text {col }}$ for the NLC-I and NLC-II, respectively, as a function of the positron energy. Being integrated in the energy interval 2 to $22 \mathrm{MeV}$, results are rather close to those of [1]. Possible techniques to increase the yield were proposed in [7]. To study those, the three target geometries and different 'collection radii are explored in a wider energy region. Positron yields from the copper targets of three configurations are presented in Figure 2 through Figure 5 as a ratio to those from the disc tungsten target. Table 2 gives the ratios for the disc, cylinder and cone copper targets for two collection radii for NLC-I and NLC-II.

Table 2: Ratio of the positron yield in the 2 to $22 \mathrm{MeV}$ energy interval from the copper targets to that from the disc tungsten target.

\begin{tabular}{|l|cccc|}
\hline Target & Disc & Cyl-4 & Cyl-6 & Cone \\
\hline & \multicolumn{5}{|c|}{$\mathrm{R}_{\text {col }}=5 . \mathrm{mm}$} \\
NLC-I & 0.55 & 0.53 & 0.54 & 0.54 \\
NLC-II & 0.57 & 0.53 & 0.57 & 0.54 \\
\hline & \multicolumn{5}{|c|}{$\mathrm{R}_{\text {col }}=10 \mathrm{~mm}$} \\
\hline NLC-I & 0.66 & 0.71 & 0.69 & 0.71 \\
NLC-II & 0.68 & 0.71 & 0.71 & 0.72 \\
\hline
\end{tabular}


Positron yield from copper is about 55 to $72 \%$ of that from tungsten in the energy interval 2 to $22 \mathrm{MeV}$. As expected for given parameters, the yields from the copper targets are lower compared to those from the tungsten. At the same time, the yield from a cone copper target with $\mathrm{R}_{c o l}=10 \mathrm{~mm}$ is rather close to the design goal. For a fixed electron beam intensity, the main gain with copper can come from the thermal, mechanical and shielding considerations.

\section{Thermal and Structural Analyses}

Energy deposition density in tungsten and copper targets $6 \mathrm{~mm}$ in radius is shown in Figures 6 and 7, respectively. One can see that the copper target has less energy deposited per unit volume. On the other hand, integral energy depositions are rather close to each other for the same target lengths as shown in Table 3.

Table 3: Fraction of the beam energy (\%) deposited in tungsten and copper disc targets of different lengths $L$ (in units of the radiation length $L_{R}$ ). Last column shows the peak energy deposition density $\epsilon_{\max }$ for the $4 \mathrm{~L}_{R}$ thick target.

\begin{tabular}{|l|c|cccc|c|}
\hline & & $\mathrm{L}=2$ & 4 & 6 & 8 & $\epsilon_{\max }(\mathrm{J} / \mathrm{g})$ \\
\hline NLC-I & $\mathrm{W}$ & 4.0 & 20.6 & 43.7 & 64.0 & 67 \\
\hline NLC-I & $\mathrm{Cu}$ & 6.7 & 29.1 & 55.2 & 74.5 & 29 \\
\hline NLC-II & $\mathrm{W}$ & 2.5 & 15.0 & 36.2 & 56.9 & 73 \\
\hline NLC-II & $\mathrm{Cu}$ & 4.1 & 21.7 & 46.5 & 67.7 & 35 \\
\hline
\end{tabular}

High energy deposition in targets cause high temperature and pressure at the beam axis, and this disturbance propagates outwards as a shock wave which can result in crack formation and fracture [8]. The CERN Antiproton Accumulator target sustained a maximum energy deposition of approximately 185 Joules per gram for tungsten [9]. Rhenium and tungsten(75\%)-rhenium(25\%) alloy demonstrated better behaviour $[1,9,10]$. Both detailed calculations [8] and experience [10,11] have shown that copper sustains much higher energy deposition density, in excess of $500 \mathrm{~J} / \mathrm{g}$. Observed with a $120 \mathrm{GeV}$ proton beam $\left(1.6 \times 10^{12}\right.$ protons per $1.6 \mu \mathrm{sec}$ pulse every $2.4 \mathrm{sec}$ ) peak energy deposition in copper is $512 \mathrm{~J} / \mathrm{g}$ with no sign of damage over long periods of repeatative irradiation, with no structural changes up to the melting point limit of $613 \mathrm{~J} / \mathrm{g}$ [12]. It is explained by the fact that only about $5 \%$ of the total energy deposition density in copper is converted into mechanical energy resulting in the pressure of about a few GPa (compare to Young's modulus for copper of $123.5 \mathrm{GPa}$ ) [8]. Currently the Pbar Source target at Fermilab is made of nickel with no target depletion effects observed for the peak energy deposition of $615 \mathrm{~J} / \mathrm{g}$.[10]. A preliminary ANSYS stress analysis in a copper target $(\mathrm{R}=6 \mathrm{~mm})$ for the NLC-II beam parameters gives an equivalent stress of about $1 \mathrm{GPa}$ immediately 
for the NLC-II beam parameters gives an equivalent stress of about $1 \mathrm{GPa}$ immediately after the first bunch and the maximum displacement of about $0.014 \mathrm{~mm}$ at the downstream end of the target.

Calculated peak energy deposition densities in the tungsten alloy targets are rather high. For this reason; special mitigating measures are proposed in [1] to prevent target destruction: a spoiler to increase the initial beam spot size and a target rotation with a high speed. Nevertheless, it is unlikely that the tungsten-based targets can handle a few times higher electron beam intensity compared to that of Table 1.

Contrary, the calculated above peak energy density in copper is about $7 \%$ of the corresponding melting point limit (a real limit for copper as per [8,10,11, 12]). The use of copper can drastically simplify the target operation: no spoilers, no target rotations. With the current proposal, the tungsten target provides about $40 \%$ higher positron yield, with only a factor of two reserve for further increasing of the production rate. At the same time, copper has at least a factor of fifteen margin, which allows an increase of the positron yield just by using more intense electron beam. One can get up to $3 \times 10^{11}$ positrons per bunch with a copper target and even more with the nickel target with an appropriate cooling system provided.

In a thermal analysis with ANSYS the effective cooling system with $\Delta \mathrm{T}=0$ at the target outer radius was assumed. Figure 8 shows a two-dimensional maximum temperature distribution in the copper target $0.4 \mathrm{sec}$ after the beginning of the irradiation. Figure 9 shows the time dependence of maximum temperature in the copper target with a steady-state regime reached after about $0.3 \mathrm{sec}$. One can see that with a good cooling system the maximum temperature in the target is $\approx 450^{\circ} \mathrm{C}$, that allows one to stay with a stationary device.

\section{Shielding}

A copper target has another advantage, lower neutron yield, which reduces the required shielding. Calculated with the MARS code, hadron $(\mathrm{E}>14 \mathrm{MeV})$ and lowenergy neutron $(\mathrm{E}<14 \mathrm{MeV})$ fluxes around tungsten and copper targets are presented in Table 4. The neutron yield is almost 6 times lower for the copper target, that results in a more compact target zone shielding. Estimated residual dose rate for the copper target is lower compared to the tungsten one.

Table 4: Particle fluxes around the tungsten and copper targets $\left(4 \mathrm{~L}_{R}\right.$ long and $6 \mathrm{~mm}$ radius) irradiated with $6.22 \mathrm{GeV}$ electron beam at $120 \mathrm{~Hz}$ rate.

\begin{tabular}{|l|l|l|}
\hline Target & $\Phi_{n}\left(\mathrm{~cm}^{-2} \mathrm{~s}^{-1}\right)$ & $\Phi_{h}\left(\mathrm{~cm}^{-2} \mathrm{~s}^{-1}\right)$ \\
\hline $\mathrm{W}$ & $6.25 \cdot 10^{12}$ & $4.72 \cdot 10^{11}$ \\
\hline $\mathrm{Cu}$ & $1.04 \cdot 10^{12} \cdot$ & $4.39 \cdot 10^{11}$ \\
\hline
\end{tabular}




\section{Conclusions}

Copper is suggested as a possible material for the positron production target with the yield close to the tungsten one. In contrast to tungsten, copper is farther from the shock-wave limit and has much better thermal properties. A copper target can be designed as a stationary unrotated cylinder with intensive cooling. With a copper target it is possible to increase further positron yield using a more intense $e^{-}$beam. Hadron and low-energy neutron yield is lower for the copper target in comparison with the tungsten one, reducing the volume of the required shielding.

\section{Acknowledgments}

The authors wish to thank Mike Foley, Bruce Hoffman and Mark Reichanadter for their help with the ANSYS thermal calculations, Igor Novitski for the target stress analysis and Jim Holt for useful discussions.

\section{References}

[1] "NLC ZDR Report, March Workbook" (1995). Current version is in preparation.

[2] H. Tang, private communication, April 1996.

[3] W. Nelson, H. Hirayama and D. Rogers, "The EGS-4 Code System", SLAC Report-265 (1985).

[4] "GEANT, Detector Description and Simulation Tool”, CERN, Geneva (1994).

[5] N. V. Mokhov, "The MARS code system Users Guide, version 13(95)", Fermilab-FN-628 (1995).

[6] “ANSYS User's Manual”, Vol. I and II, SASI Publications (1994).

[7] R. Donahue and W. Nelson, "Alternative Positron Target Design for ElectronPositron Colliders", SLAC-Pub-5702 (1991).

[8] Z. Tang and K. Anderson, "Shock Waves in P-bar Target", Fermilab-TM-1763 (1991).

[9] Proc. of "High Intensity Targeting Workshop", Fermilab, April 28-30 (1980).

[10] S. O'Day, F. Bieniosek, and K. Anderson, "New Target Results from the FNAL "Antiproton Source", Proc. of the 1993 IEEE Particle Accelerator Conference, 3096 (1993). 
[11] F. M. Bieniosek, "Effect of Melting on Target Performance", Fermilab Pbar Note-512 (1991).

[12] S. O'Day, private communication, April 1996.
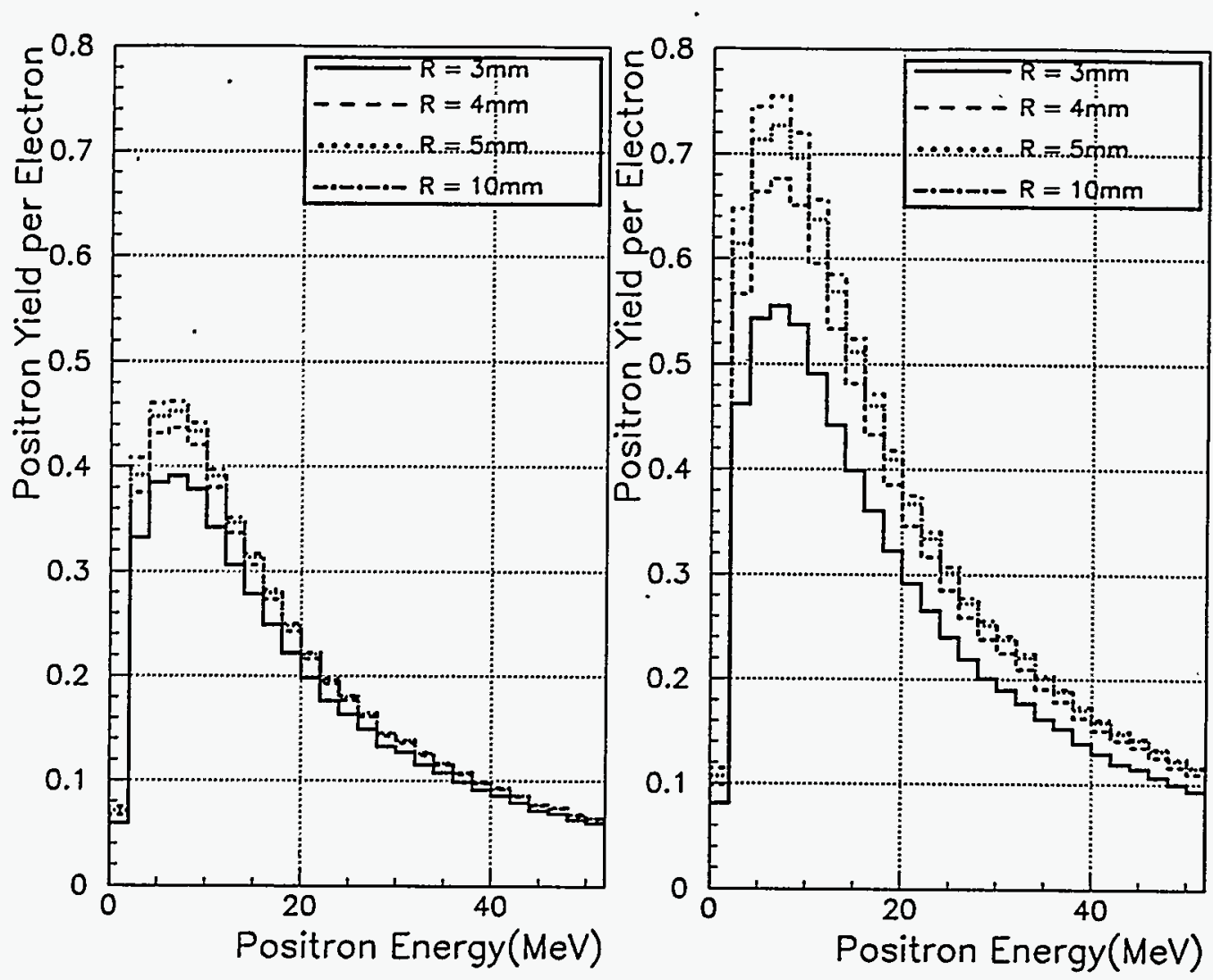

Figure 1: Positron yield per $\triangle \mathrm{E}=2 \mathrm{MeV}$ per one electron for the disc tungsten target. a) $\mathrm{E}_{e^{-}}=3.11 \mathrm{GeV}, \sigma_{x}=\sigma_{y}=1.2 \mathrm{~mm}$ (left); b) $\mathrm{E}_{e^{-}}=6.22 \mathrm{GeV}, \sigma_{x}=\sigma_{y}=1.6 \mathrm{~mm}$ (right). 

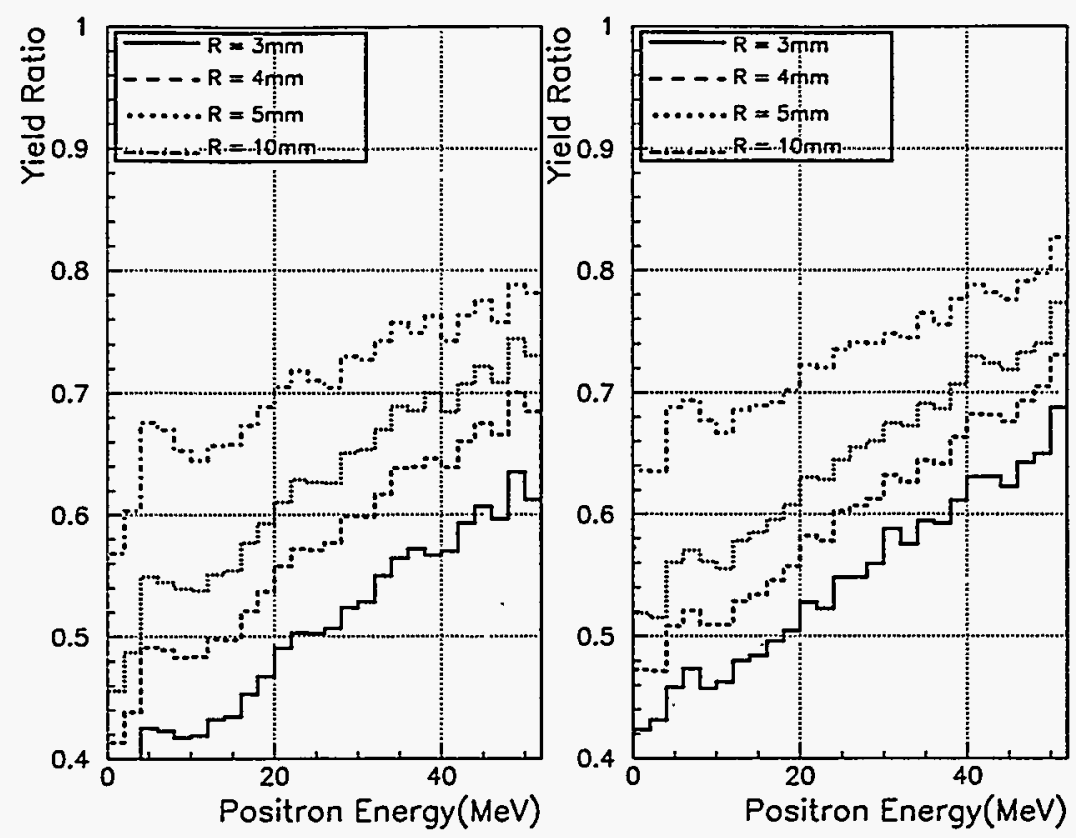

Figure 2: Ratio of positron yield per $\Delta \mathrm{E}=2 \mathrm{MeV}$ from the disc copper target to that from the tungsten one. a) $\mathrm{E}_{e^{-}}=3.11 \mathrm{GeV}, \sigma_{x}=\sigma_{y}=1.2 \mathrm{~mm}$ (left); b) $\mathrm{E}_{e^{-}}=6.22 \mathrm{GeV}$, $\sigma_{x}=\sigma_{y}=1.6 \mathrm{~mm}$ (right).
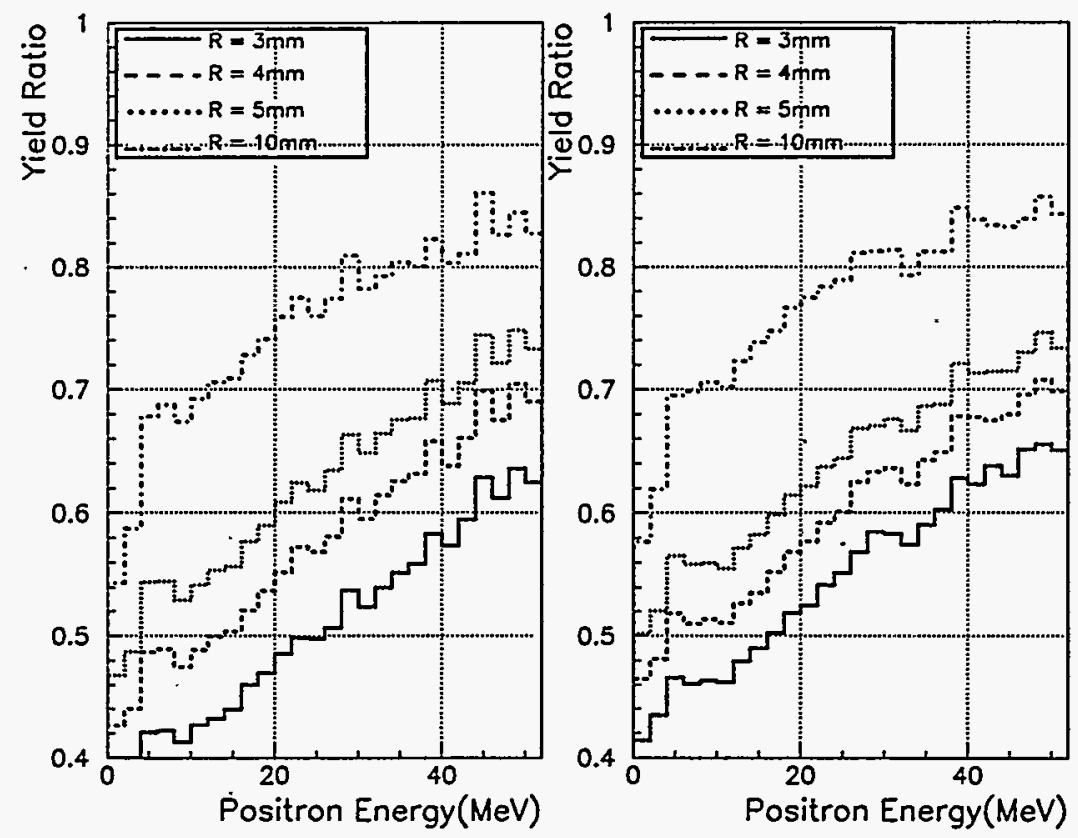

Figure 3: Ratio of positron yield per $\Delta \mathrm{E}=2 \mathrm{MeV}$ from the cylinder copper target ( $\mathrm{R}=6 \mathrm{~mm}$ ) to that from the tungsten disc. a) $\mathrm{E}_{e^{-}}=3.11 \mathrm{GeV}, \sigma_{x}=\sigma_{y}=1.2 \mathrm{~mm}$ (left); b) $\mathrm{E}_{e^{-}}=6.22 \mathrm{GeV}, \sigma_{x}=\sigma_{y}=1.6 \mathrm{~mm}$ (right). 



Figure 4: Ratio of positron yield per $\triangle \mathrm{E}=2 \mathrm{MeV}$ from the cylinder copper target ( $\mathrm{R}=4 \mathrm{~mm}$ ) to that from the tungsten disc. a) $\mathrm{E}_{e^{-}}=3.11 \mathrm{GeV}, \sigma_{x}=\sigma_{y}=1.2 \mathrm{~mm}$ (left); b) $\mathrm{E}_{e^{-}}=6.22 \mathrm{GeV}, \sigma_{x}=\sigma_{y}=1.6 \mathrm{~mm}$ (right).
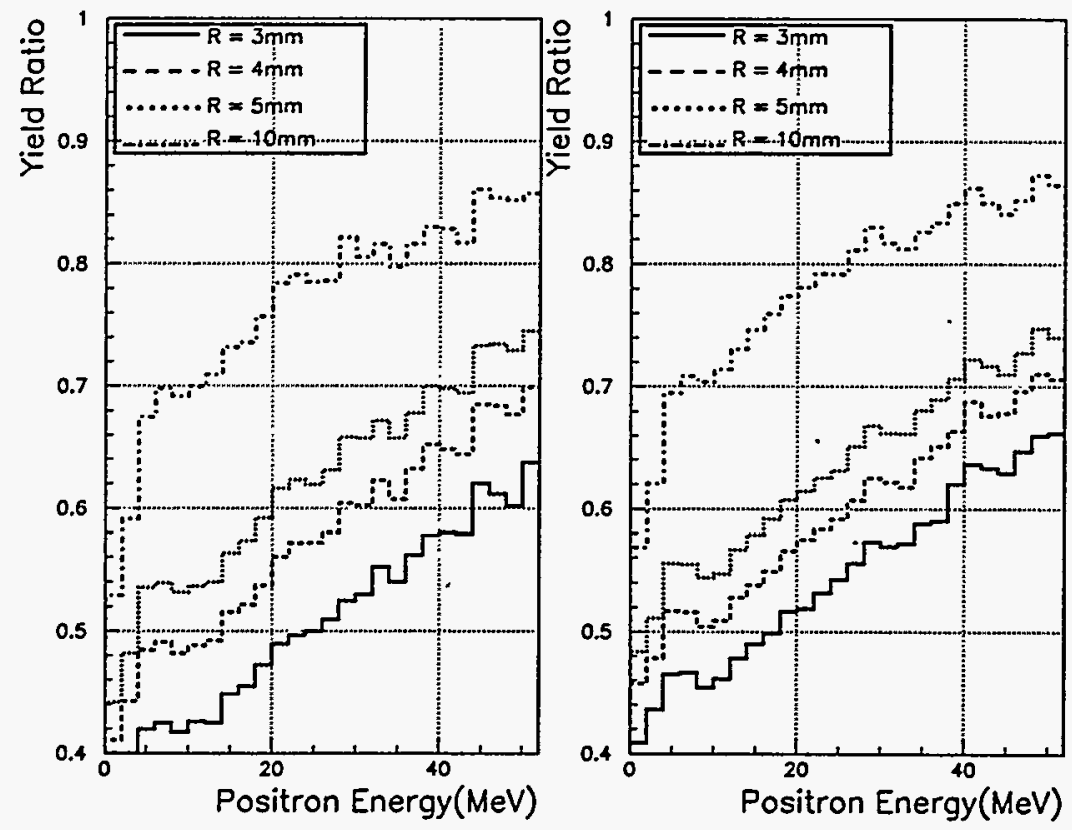

Figure 5: Ratio of positron yield per $\Delta \mathrm{E}=2 \mathrm{MeV}$ from the cone copper target $\left(\mathrm{R}_{1}=5 \mathrm{~mm}, \mathrm{R}_{2}=3 \mathrm{~mm}\right.$ ) to that from the tungsten disc. a) $\mathrm{E}_{e^{-}}=3.11 \mathrm{GeV}, \sigma_{x}=\sigma_{y}=$ $1.2 \mathrm{~mm}$ (left); b) $\mathrm{E}_{e^{-}}=6.22 \mathrm{GeV}, \sigma_{x}=\sigma_{y}=1.6 \mathrm{~mm}$ (right). 

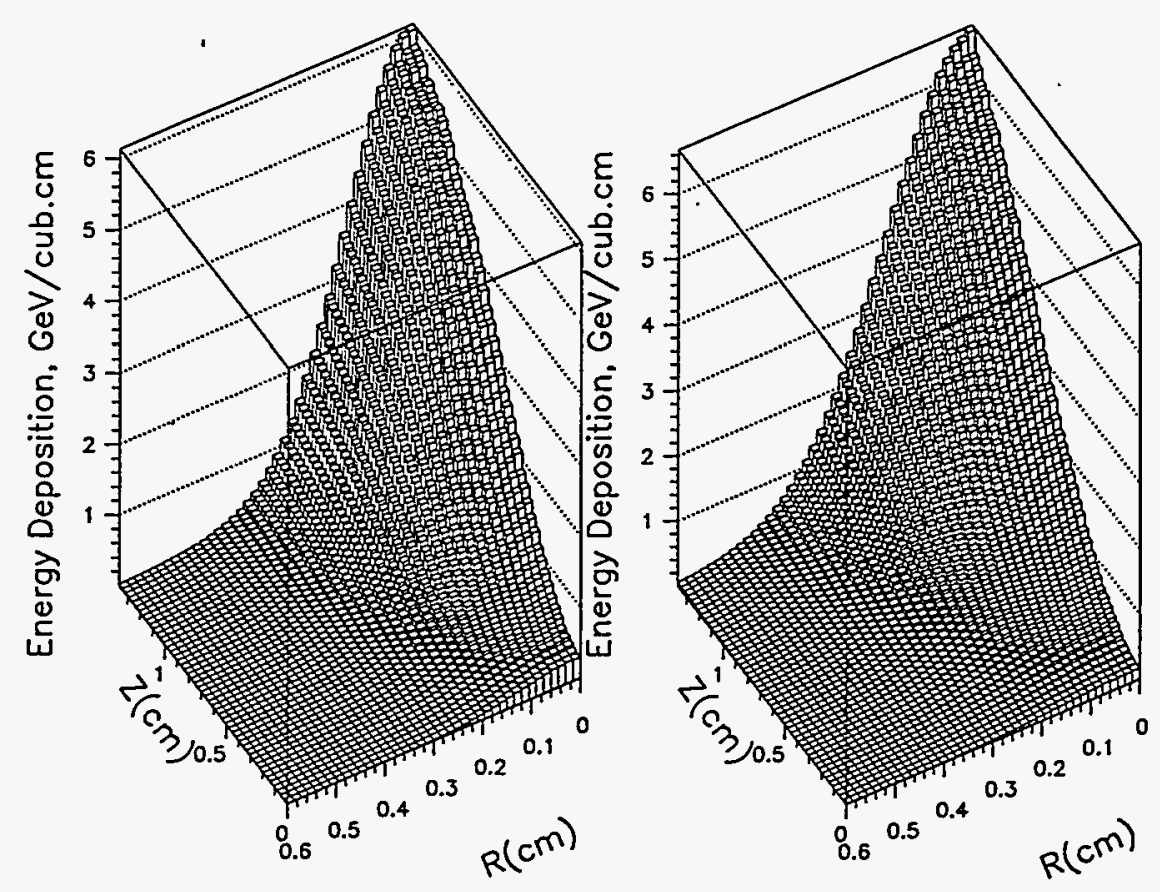

Figure 6: Energy deposition in a tungsten target $(\mathrm{R}=6 \mathrm{~mm})$ for NLC-I and NLC-II: a) $\mathrm{E}_{e^{-}}=3.11 \mathrm{GeV}, \sigma_{x}=\sigma_{y}=1.2 \mathrm{~mm}$ (left); b) $\mathrm{E}_{e^{-}}=6.22 \mathrm{GeV}, \sigma_{x}=\sigma_{y}=1.6 \mathrm{~mm}$ (right).

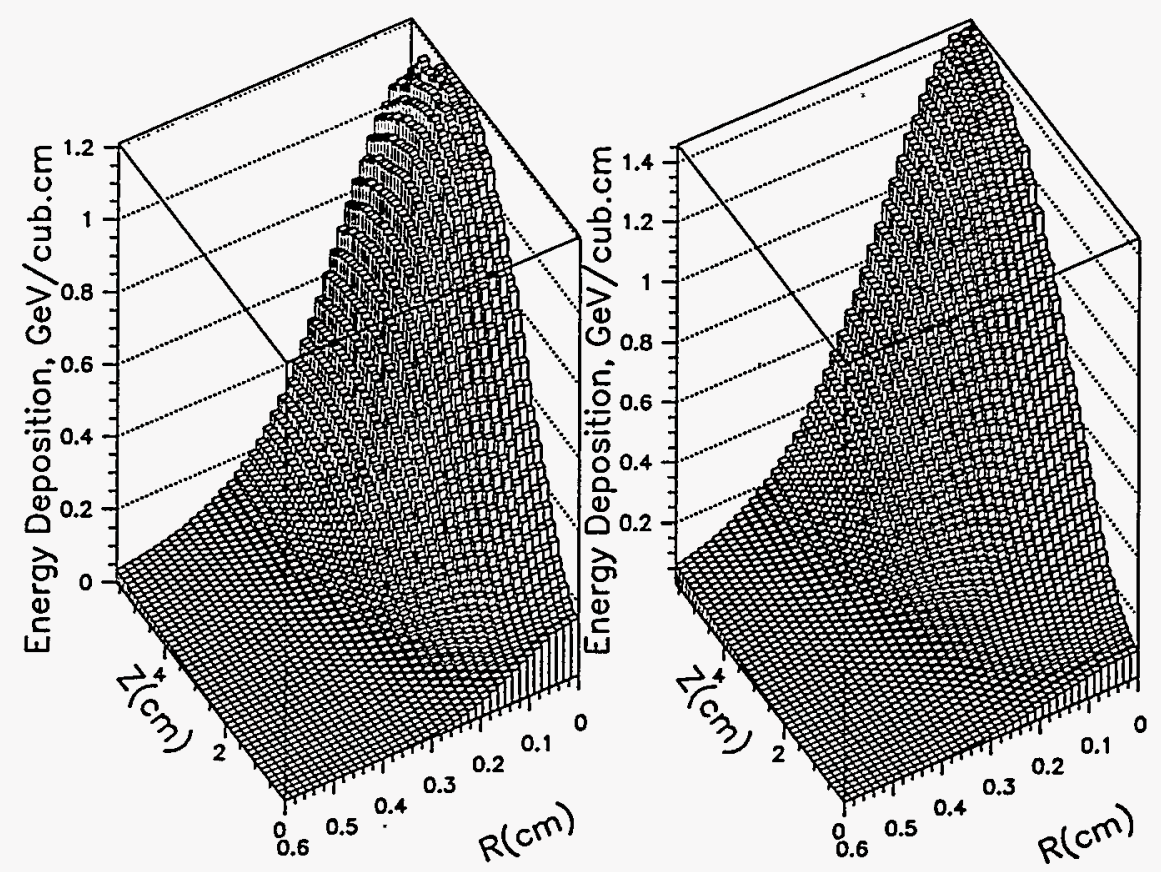

Figure 7: Energy deposition in a copper target ( $R=6 \mathrm{~mm})$ for NLC-I and NLC-II: a) $\mathrm{E}_{e^{-}}=3.11 \mathrm{GeV}, \sigma_{x}=\sigma_{y}=1.2 \mathrm{~mm}$ (left); b) $\mathrm{E}_{e^{-}}=6.22 \mathrm{GeV}, \sigma_{x}=\sigma_{y}=1.6 \mathrm{~mm}$ (right). 


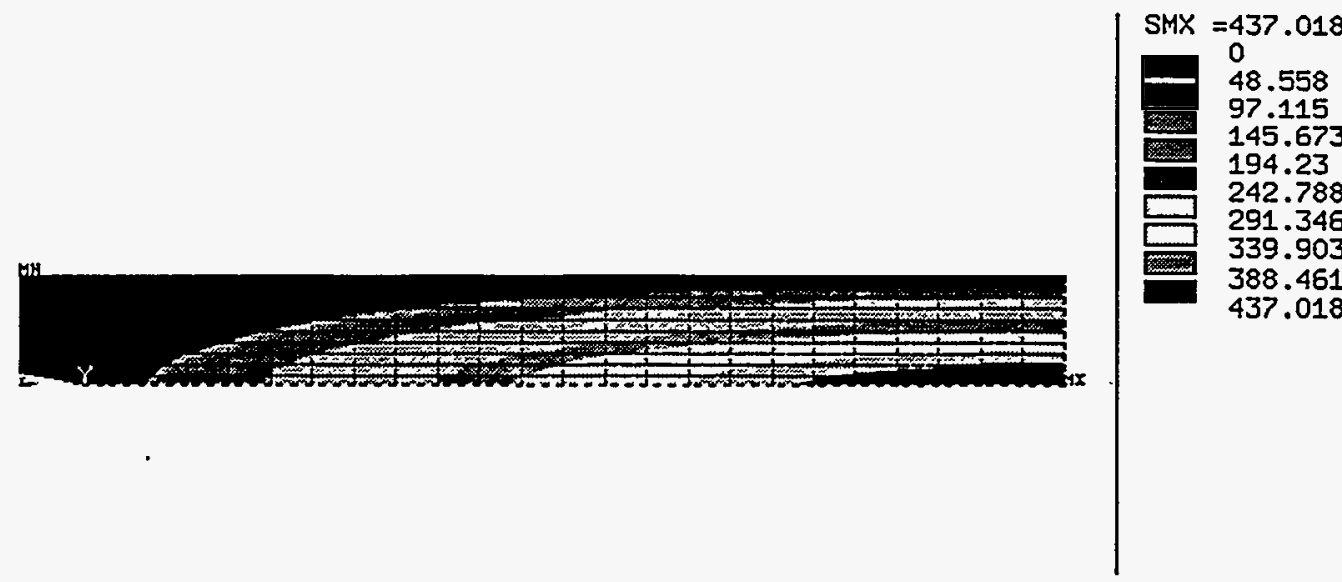

Figure 8: Temperature distribution after the pulse in a copper target $(\mathrm{R}=6 \mathrm{~mm})$ for NLC-II. $\mathrm{E}_{e^{-}}=6.22 \mathrm{GeV}, \sigma_{x}=\sigma_{y}=1.6 \mathrm{~mm}$.

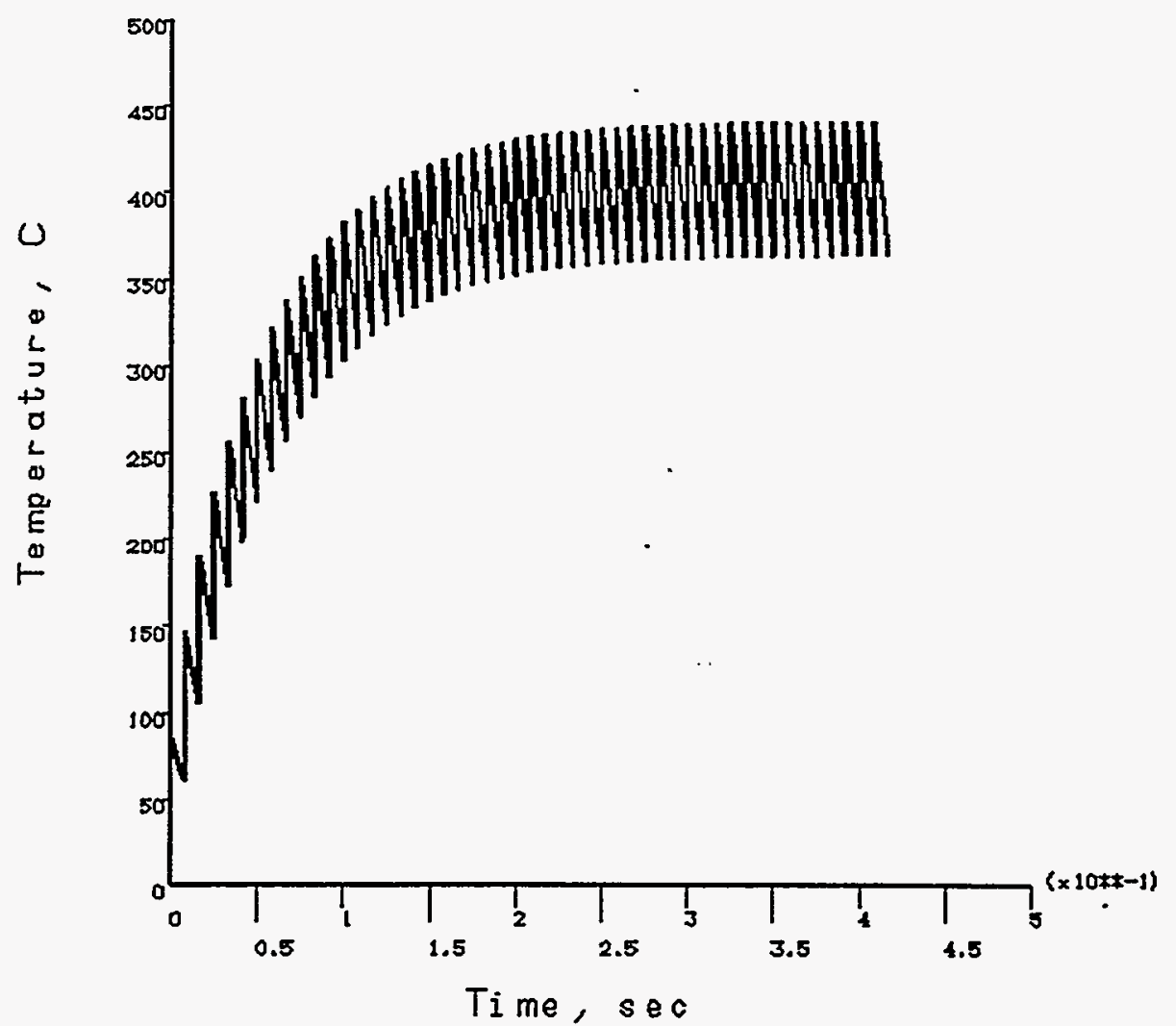

- Figure 9: Time dependence of maximum temperature in a copper target ( $\mathrm{R}=6 \mathrm{~mm})$ for NLC-II. $\mathrm{E}_{e^{-}}=6.22 \mathrm{GeV}, \sigma_{x}=\sigma_{y}=1.6 \mathrm{~mm}$. 